\title{
INTEGRASI PEMANFAATAN MEDIA PEMBELAJARAN BERBASIS ADOBE FLASH DENGAN LINGKUNGAN UNTUK MENINGKATKAN MINAT BELAJAR BIOLOGI
}

\author{
Riskey Oktavian ${ }^{1}$, Riantina Fitra Aldya ${ }^{2}$ \\ ${ }^{1}$ Manager Riset Institute of Asean Studies, Universitas Kristen Indonesia \\ ${ }^{2}$ Universitas Tribhuwana Tunggadewi \\ E-mail: riantinafitra@unitri.ac.id
}

\begin{abstract}
This study aims to determine whether the integration of learning media with the environment is able or not to increase student interest in learning. This research uses meta-analysis-data in the form of descriptive explorative qualitative, which is related to learning media and the environment. Data is collected from various secondary data, which is combined and analyzed by calculating the same percentage of findings for similar problems. The results show that this integration can increase student interest in learning, especially when learning about Science at the Botanical Gardens School, which is characterized by increasing positive behaviors and feelings, also increasing attention, and involvement of students in learning.
\end{abstract}

Keywords: integration; learning media; adobe flash; environment; learn interest.

\begin{abstract}
ABSTRAK
Penelitian ini bertujuan untuk mengetahui apakah integrasi media pembelajaran dengan lingkungan mampu atau tidak untuk meningkatkan minat belajar siswa. Penelitian ini menggunakan meta-analisis-data berupa deskriptif eksploratif kualitatif, yang berhubungan dengan media pembelajaran dan lingkungan. Data dikumpulkan dari berbagai data sekunder, yang digabungkan dan dianalisis dengan menghitung persentase temuan yang sama untuk masalah serupa. Hasil penelitian menunjukkan bahwa integrasi ini dapat meningkatkan minat belajar siswa, terutama saat belajar tentang Ilmu Pengetahuan di Sekolah Taman Botani, yang ditandai dengan meningkatkan perilaku dan perasaan positif, juga meningkatkan perhatian, dan keterlibatan peserta didik dalam belajar.
\end{abstract}

Kata kunci: integrasi; media pembelajaran; adobe flash; lingkungan; minat belajar.

\section{PENDAHULUAN}

Sistem pendidikan yang berkualitas tidak terlepas dari keberhasilan guru dalam merancang dan melaksanakan proses pembelajaran, namun tidak semua pembelajaran dapat di bawa ke dalam kelas. Salah satu mata pelajaran yang bersifat penting adalah Biologi, ini bersifat penting mengingat banyaknya materi yang disajikan bersifat kompleks untuk dipelajari. Koba \& Tweed (2009), menyatakan bahwa terdapat lima topik biologi yang memiliki tingkat kesulitan tinggi yaitu reproduksi, fotosintesis, seleksi alam, genetika molekuler, dan juga interaksi antar makhluk hidup. Kompleksitas materi yang bersifat abstrak ini akan membutuhkan suatu medium untuk menyalurkan informasi secara menyeluruh. Dimitrios et al., (2005) juga menekankan bahwa suatu pengajaran akan lebih baik jika diperkuat bila tidak hanya murni dilakukan secara teoritis, namun juga digabungkan secara visual dan

Cara mengutip: Oktavian, R., \& Aldya, R.F. (2020). Integrasi Pemanfaatan Media Pembelajaran Berbasis Adobe Flash dengan Lingkungan untuk Meningkatkan Minat Belajar Biologi. Inteligensi: Jurnal Ilmu Pendidikan, 3(1), 40-46 
interaktif, karena dengan cara ini siswa bisa mendapatkan pemahaman yang lebih dalam tentang subjek yang dipelajari.

Salah satu materi pembelajaran Biologi kelas $\mathrm{X}$ di sekolah yang bersifat kompleks dan membutuhkan bantuan media agar pembelajarannya dapat maksimal adalah materi Spermatophyta. Memiliki pokok bahasan yang memiliki kesulitan tinggi, salah satunya yaitu "reproduksi". Suraida (2012), menekankan bahwa materi ini dikatakan sulit karena mempertimbangkan tingginya kerumitan dan kompleksitas materinya yang terbagi dalam sub divisi Gymnospermae dan Angiospermae, serta berkaitan erat dengan dasar-dasar ilmu biologi, seperti bahasa ilmiah, perbedaan morfologi, anatomi, reproduksi, maupun ekologinya. Namun tidak hanya sekedar melalui media, pembelajaran yang terkait dengan tumbuhan terutama tumbuhan berbiji (Spermatophyta), tentu saja sangat baik jika dihadapkan pada lingkungan yang sebenarnya. Seperti yang dikemukakan oleh Suryadharma \& Suyanto (1993), bahwa proses pembelajaran Biologi akan lebih berhasil apabila objek yang dipelajari merupakan objek nyata di lingkungan sekitarnya. Salah satu lingkungan terbaik untuk materi ini adalah melalui kebun raya atau sekolah yang berbasis kebun raya (botanical garden school) karena dapat langsung berhadapan dengan tanaman secara langsung.

Namun seperti yang dikemukakan sebelumnya, terdapat banyak kendala terkait dengan kompleksitas materi, dimana terdapat banyak konten yang harus dipelajari sehingga tidak ada cukup waktu untuk melakukan eksperimen dan penyelidikan yang melibatkan siswa secara terus-menerus (Koba \& Tweed, 2009).
Selain itu kompleksitas materi juga dapat menyebabkan rendahnya minat belajar, karena sulitnya memahami suatu materi menyebabkan siswa menjadi malas, dan tidak bersemangat, sehingga dibutuhkan dukungan instruksional yang inovatif, menyediakan cara visual dan stimulasi yang menarik terutama untuk memahami konsep abstrak dan kompleks (Akkuzu \& Ackay, 2011). Hal ini didukung oleh penelitian Tan \& Waugh (2013: 17) menunjukan pentingnya pembelajaran melalui visualisasi agar dapat mengklarifikasi pada aspek pemahaman, meningkatkan minat, dan keterlibatan nyata mereka terhadap objek di lingkungan sekitar. Ini membuktikan bahwa pelajaran Biologi tidak cukup hanya menekankan objek nyata, melainkan membutuhkan pemanfaatan TIK agar pembelajaran dapat berlangsung seefektif mungkin.

Salah satu pemanfaatan TIK dapat berupa media pembelajaran berbasis adobe flash. Adobe flash dipilih karena popularitasnya dalam membuat animasi yang bersifat sederhana, proses pembuatannya tidak memerlukan waktu lama, namun tetap menghasilkan pembelajaran yang interaktif karena hanya membutuhkan ide yang cukup unik dan menarik, sehingga materi Spermatophyta dapat diinterpretasikan melalui animasi gambar, suara, video, film, website, presentasi, game, dan lain sebagainya sehingga materinya menjadi lebih hidup, menarik, dan menyenangkan (Hasrul, 2011), serta dapat membantu kebutuhan peserta didik yang berbeda-beda baik secara auditori, visual, atau kinestetik. Namun, berdasarkan uraian tersebut perlu diketahui apakah pemanfaatan teknologi dalam bentuk medial berbasis adobe flash, yang diimplementasikan penggunaannya 
di lingkungan sekolah kebun raya (botanical garden school) dapat benarbenar meningkatkan minat belajar peserta didik terkhusus pada materi Spermatophyta, karena beberapa pokok bahasan seperti membedakan kelompok tumbuhan gymnospermae dan juga angiospermae dalam tumbuhan berbiji tentu saja akan sangat baik jika siswa dapat mengamatinya secara langsung dimulai dari bentuk daun, bunga, biji, batang dan sebagainya. Peserta didik dapat memilih dan mengidentifikasi ciri-ciri tanaman yang dipilihnya di lingkungan kemudian dengan banntuan media pembelajaran berbasis adobe flash, peserta didik dapat mengakses informasi sebanyak-banyaknya dengan bantuan informasi, representasi maupun transformasi tugas di dalam media.

\section{METODE PENELITIAN}

Metode yang digunakan dalam artikel ini adalah meta-analisis jurnal. Meta- analisis menunjukkan kekuatan hubungan variabel untuk studi yang dimasukkan dalam analisis. Teknik ini menekankan hasil di berbagai studi sebagai lawan dari hasil dari satu penyelidikan, dimana berbagai macam jurnal yang berhubungan dengan integrasi lingkungan, media pembelajaran dan pendidik dikumpulkan kemudian dikaji dan ditarik menjadi suatu kesimpulan.

\section{HASIL DAN PEMBAHASAN}

Adobe flash menurut Murawan (2015) adalah program yang sangat populer untuk membuat animasi 2D berbasis vektor. Ditambahkan oleh Reimers \& Stuart (2007: 365), sebagai aplikasi yang menggunakan grafis vektor dan kombinasi bahasa pemrograman yang disebut Actionscript serta animasi berbasis frame sederhana yang paling banyak digunakan untuk membuat animasi bergerak interaktif. Menurut Wallace (2006), terdapat empat kategori yang harus dipenuhi untuk memenuhi kebutuhan peserta didik yaitu: (1) Representasi (representation), memberikan representasi gagasan maupun proses yang sulit atau tidak mungkin untuk ditampilkan tanpa teknologi; (2) Informasi (information), menyediakan akses terhadap data dan konten yang sebelumnya tidak mungkin digunakan di ruang kelas; (3) Transformasi (transformation), mengubah sifat tugas di mana peserta didik terlibat untuk diikutsertakan, melalui serangkaian langkah tertentu; (4) Kolaborasi (collaboration), memfasilitasi komunikasi dan kolaborasi dengan rekan sejawat dan ahli. Keempat unsur ini dapat dicapai melalui sebuah program perangkat lunak salah satunya adalah Adobe flash.

Felder \& Brent (2015), menyatakan bahwa banyak sekali studi yang mengkategorikan ragam cara belajar peserta didik ke dalam empat skala yaitu Active, Sensing, Visual dan Sequential. Berdasarkan hasil survey pembelajar sains memiliki presentase pembelajar Active sebesar $65 \%$, Sensing sebesar $81 \%$, Visual sebesar 79\% dan Sequential sebesar 67\%, sedangkan salah satu universitas di Puerto Rico berdasarkan survey selama 3 semester, menunjukkan bahwa pembelajar Biologi presentase pembelajar Active sebesar 58\%, Sensing sebesar 75\%, Visual sebesar $72 \%$ dan Sequential sebesar $81 \%$. Ragam cara belajar ini diyakini bahwa peserta didik akan lebih nyaman untuk belajar dengan menggunakan cara belajarnya sendiri. Gaya belajar dari peserta didik diduga terkait dengan 
preferensi yang kuat dalam mengatasinya menggunakan modul pembelajaran interaktif. Penelitian oleh Jamwal (2012: 19) menunjukkan bahwa peserta didik cenderung memilih menggunakan modul interaktif, dimana dari total 128 peserta didik, 114 peserta didik memilih menggunakan media interaktif $(89,06 \%)$, 85 peserta didik memilih bekerja dalam kelompok (66\%), 37 peserta didik memilih membaca buku (29\%), 29 peserta didik memilih mengerjakan tugas tertulis $(23 \%)$.

Alasan dari pemilihan tersebut dikarenakan dapat mengatasi semua gaya belajar peserta didik, selain itu juga dapat meningkatkan minat belajar peserta didik ketika topik yang disajikan melalui cara yang membuat siswa menyukainya, dan minat peserta didik terhadap topik tersebut juga dapat mempengaruhi, sehingga dapat dikatakan minat juga bergantung pada topik itu sendiri. Penelitian Ravi \& Malathy (2010: 45) menambahkan bahwa minat belajar juga dipengaruhi oleh interaktivitas yang dimunculkan pada teknologi instruksional, dimana teknologi pembelajaran yang digunakan di kelas berupa multimedia (di dalamnya terdapat audio, video, teks, grafik, dan gambar) yang disampaikan melalui informasi digital menggunakan perangkat lunak Macromedia Flash (sekarang telah menjadi Adobe flash). Menggunakan kelompok kontrol dan eksperimen yang masing-masing terdiri dari 25 orang, menunjukkan skor perolehan rata-rata kelompok kontrol sebesar 18,4\% dan kelompok eksperimen sebesar 30,4\%. Penelitian ini menunjukkan bahwa kelompok eksperimen 12\% lebih tinggi dari kelompok kontrol, dikarenakan belajar melalui multimedia sangat efektif dengan roperti utama yaitu interaktivitas, yang memunculkan minat sehingga merangsang pembelajaran antar pengguna yang mendorong siswa untuk mencari informasi, menerapkan tugas pengetahuan dan tugas ulang (berdasarkan umpan balik yang diberikan).

Hal tersebut memenuhi semua unsur esensial dari Laurillard (1985: 82) terkait pembelajaran yang efektif, unsur tersebut meliputi diskursif, adaptif, interaktif dan reflektif. Diskursif yaitu memungkinkan diskusi antara siswa dan guru sebagai bentuk reaksi dari suatu subjek/ konsep tertentu; adaptif yaitu penyesuaian oleh guru terhadap mahasiswa yang meliputi interaksi dengan lingkungan siswa; interaktif yaitu memunculkan interaksi yang menyenangkan; dan reflektif sebagai bentuk perenungan atas pengalaman belajar siswa. Keempat komponen tersebut disajikan pada gambar 1 berikut:

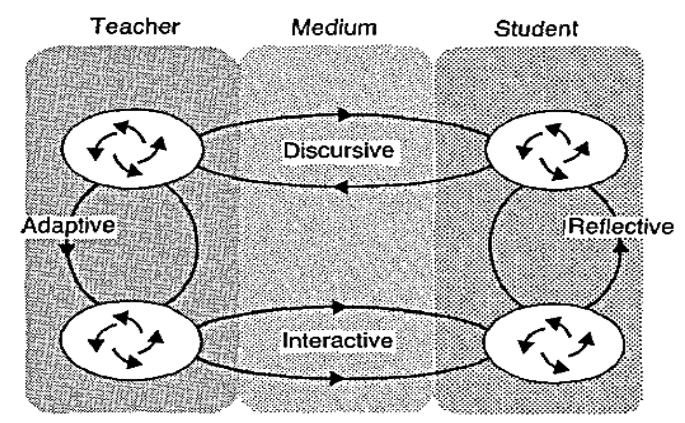

\section{Gambar 1. Proses Pembelajaran Ideal: Hubungan Komponen Esensial}

Media adobe flash mendukung semua aspek pada proses pembelajaran tersebut, karena memunculkan representasi dari apa yang masing-masing dapat berkontribusi pada aspek tersebut. Salah satu aplikasi yang dapat membantu media untuk memenuhi komponen-komponen esensial tersebut adalah melalui Adobe flash. 
Integrasi Media Pembelajaran berbasis Adobe flash dengan Lingkungan

Griffiths, et al., (2007) menyatakan bahwa guru harus mengakomodasi siswa untuk melakukan lebih banyak kontrol dan interaksi agar pembelajaran berpusat pada siswa. Retzlaff-Fürst (2016: 1848), dalam menyatakan bahwa suatu lingkungan merupakan area yang cocok untuk pembelajaran di sekolah secara eksploratif, karena menyediakan sumber untuk pengajaran interdisipliner dan tempat untuk menghasilkan keterampilan. Hal ini ditekankan oleh Ratnayaka (2016: 6), bahwa pembelajaran di luar ruang, dapat meningkatkan kepuasan dan minat siswa yang mengarah pada pemahaman lebih mendalam. Sebuah latihan menggunakan botani yang ada di lingkungan sekolah akan memperkuat area pengetahuan tertentu mengenai kelompok tanaman utamanya.

Sebuah survei dilakukan kepada 198 siswa, mengevaluasi keuntungan pengetahuan yang dirasakan siswa melalui nilai kuis dari latihan tur di lingkungannya, beberapa siswa melaporkan bahwa kegiatan tersebut memunculkan perilaku positif sebagai hasil kombinasi dari perasaan positif, pembelajaran melalui pengalaman, dan peningkatan minat. Dilihat melalui nilai kuis dari latihan tersebut, $11 \%$ lebih besar dari nilai kuis dari pembelajaran konvensional. Hal ini mungkin dikarenakan minat berkontribusi terhadap peningkatan persepsi dan pengetahuan aktual siswa. Siswa melaporkan bahwa pengetahuan mereka meningkat, dengan total $66 \%$ mengenai Gymnosperma lokal, dan $87 \%$ mengenai Angiosperma lokal (Monocots dan Eudicots); namun peningkatan mengenai manfaat ekonomi pohon hanya $11 \%$, rata- rata di seluruh dua semester. Berdasarkan hasil survei peningkatan tersebut dikarenakan (a) munculnya minat siswa; (b) munculnya motivasi mereka untuk mengajukan pertanyaan dan (c) keterlibatan mereka dengan materi yang mereka tangani.

Materi seperti Spermatophyta sangat baik dilakukan menggunakan obyek nyata karena terkait dengan morfologi tanaman yang dapat diamati secara langsung. Seperti pada tanaman gymnosperma dan angiospermae sehingga dapat dibedakan berdasarkan: (1) habitusnya apakah terna, semak, perdu, maupun pohon; (2) sistem perakarannya baik serabut maupun tunggang; (3) batangnya, baik cabang maupun tidak; (4) bentuk dari daunnya seperti ukuran lebarnya, tunggal atau majemuk dan sistem pertulangannya; dan (5) bunganya (Tjitrosoepomo, 2007: 7-8). Selain itu pada angiospermae juga dapat dibedakan menjadi monokotil dan eudikotil, seperti pada gambar 2 berikut:

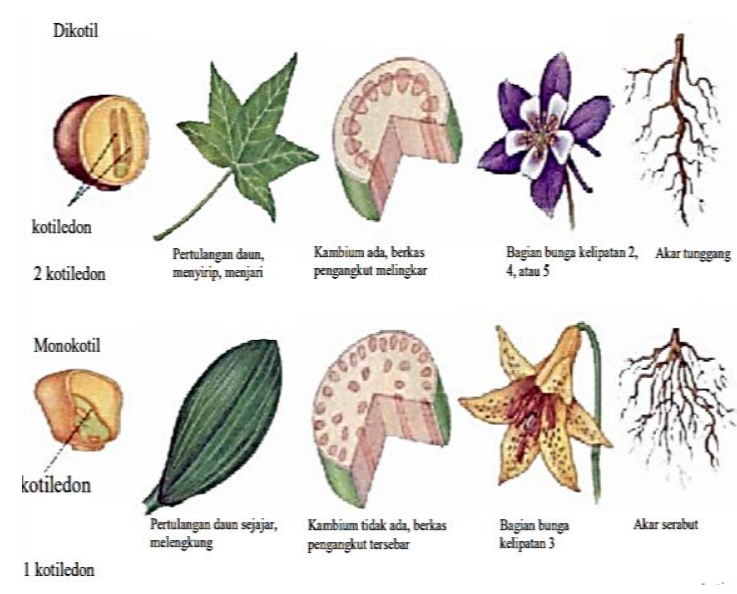

Gambar 2. Perbedaan Dikotil dan Monokotil

Hanya saja salah satu kendala mengenai pembelajaran secara langsung di lapangan adalah tidak dapat melihat secara langsung suatu proses yang rumit, misalnya proses reproduksi maupun proses fotosintesis. Hammond, et al (2014: 4), 
menyatakan bahwa guru, siswa dan lingkungan saja tidak cukup, karena juga diperlukan suatu teknologi yang mengakomodasi pembelajaran, sehingga membentuk digital learning ecosystem, yang disajikan sebagai berikut:

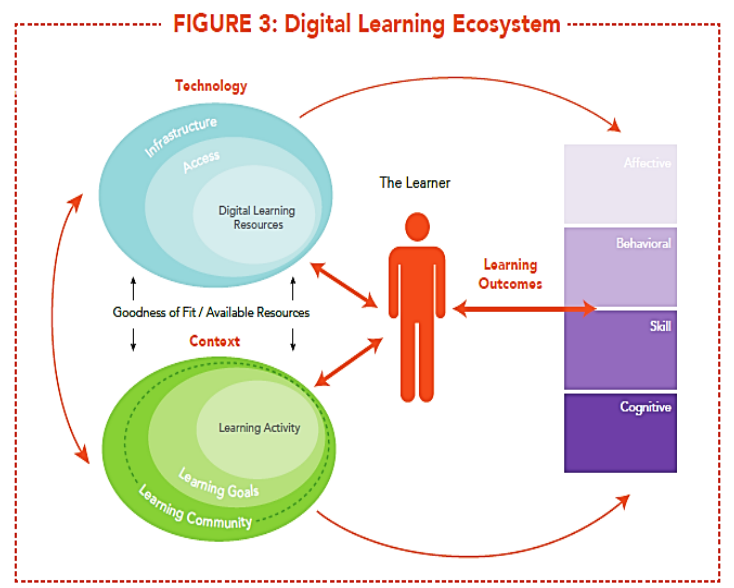

Gambar 3. Digital Learning Ecosystem

Pemanfaat media sebagai bahan ajar memiliki efek positif dalam proses belajarmengajar di dalam dan di luar kelas karena memunculkan perasaan positif dengan membentuk karakter sosial dan kerjasama antar peserta ajar serta meningkatkan minat belajar (Kamhar \& Lestari, 2019). Hasil pembelajaran yang berbeda tersebut dapat dilakukan, mulai dari afektif (misalnya pelajar minat dan motivasi), perilaku (misalnya, keterlibatan dengan pembelajaran), keterampilan, maupun kognitif. Aspek penting dari pembuatan teknologi adalah akses serta integrasinya dengan lingkungan yaitu sumber daya yang ada sebagai konteks belajar. Konteks teknologi dan pembelajaran akan berinteraksi dengan karakteristik peserta didik dan membentuk pengalaman pelajar. Perpaduan ini akan membentuk pembelajaran interaktif, penggunaan teknologi untuk mengeksplorasi dan perpaduan yang tepat antara guru dan teknologi.

\section{SIMPULAN}

Pembelajaran Biologi sangat baik sekali ketika peserta didik langsung dihadapkan pada obyek nyata, namun terdapat beberapa konten materi yang sangat rumit untuk diamati seperti materi yang terkait dengan suatu proses. Kompleksitas materi ini dapat menyulitkan peserta didik untuk belajar sehingga dapat menyebabkan menurunnya minat belajar peserta didik. Dibutuhkan suatu solusi berupa visualisasi untuk memudahkan dalam transfer informasi selama pembelajaran, yaitu dapat menggunakan media berbasis adobe flash karena kemudahannya dalam menampilkan teks, gambar, video maupun animasi, namun penggunaan media ini akan efektof ketika telah memenuhi komponen esensial dalam proses pembelajaran seperti diskursif, adaptif, interaktif dan reflektif, sehingga untuk menghasilkan pembelajaran efektif dapat melalui integrasi dengan adanya akses teknologi, konten terkait lingkungan belajar peserta didik, yang dapat meningkatkan minat belajar.

\section{DAFTAR PUSTAKA}

Akkuzu, N., \& Akcay, H. 2011. An Effective Model to Increase Student Attitude and Achievement: Narrative Including Analogies. USChina Education Review A 5 (2011). ISSN 1548-6613. pp. 612623.

Dimitrios, A., Konstantinos, P., Nikolaos, S., \& Angelo, S. 2015. Application of a New Network-enabled Solver for the Assignment Problem in Computer-aided Education. Journal of Computer Science. (1)1. ISSN 1549-3636. pp. 19-23.

Felder, R.M., and Brent, R. 2015. "Understanding the Student 
Differences,". Journal of Engineering Education, (94). 2005, pp. 57-72.

Griffiths, G., Oates, B.J. \& Lockyer, M. 2007. Evolving a Facilitation Process towards Student Centred. Learning: A Case Study in Computing. Journal of Information Systems Education, 18(4).

Hammond, L., Zielezinski, M.B., \& Goldman, S. 2014. Using Technology to Support At-Risk Students' Learning. USA: SCOPE (standford center for opportunity policy in education).

Hasrul. 2011. Desain Media Pembelajaran Animasi Berbasis Adobe Flash CS3 pada Mata Kuliah Instalasi Listrik 2. Jurnal MEDTEK. Volume 3, Nomor 2. Oktober 2011.

Jamwal, G. 2012. Effective use of Interactive Learning Modules in Classroom Study for Computer Science Education. All Graduate Plan B and other Reports. Paper 225. Pp 1-75.

Kamhar, M. Y., \& Lestari, E. 2019. Pemanfaatan Sosial Media Youtube sebagai Media Pembelajaran Bahasa Indonesia di Perguruan Tinggi. Inteligensi: Jurnal Ilmu Pendidikan. 1(2) 2019, 1-7.

Koba, S., \& Tweed, A. 2009. Hard-ToTeach Biology Concepts : A Framework to Deepen Student Understanding. USA: National Science Teachers Association.

Laurillard, D. 1993. Balancing the Media: Learning, Media and Technology. Journal of Educational Television. Volume 19, Number 2. pp.81-93.

Neo, M., Park, H., Lee, M, Soh, J., \& Oh, J. 2015. Technology Acceptance of Healthcare E-Learning Modules: A Study of Korean and Malaysian
Students' Perceptions. TOJET: The

Turkish Online Journal of

Educational Technology. Volume 14, Issue 2, April 2015.

Ratnayaka, H. H. 2017. An On-Campus

Botanical Tour To Promote Student

Satisfaction And Learning In A

University Level Biodiversity Or

General Biology Course. Article Educ. Sci. (7) 18. 2017.

Ravi, R., \& Malathy, V.A. 2010. Multimedia as an Interactive Platform in Learning Volcanoes in Social Sciences Among Upper Primary Students - An Experiment. i-manager's. Journal on School Educational Technology. (6)2. September - November 2010.

Retzlaff-Fürst, C. 2016. Biology Education \& Health Education: A School Garden as a Location of Learning \& Well-being. Universal Journal of Educational Research. Volume 4, Number 8. pp.1848-1857.

Suraida. 2012. Identifikasi Tumbuhan Penghijauan sebagai Media Belajar Biologi. Jurnal Edu-Bio. Volume 3, Tahun 2012. pp. 5564.

Suryadharma, I.G.P., \& Suyanto, S. 1993. Pembelajaran Biologi Melalui Pendekatan Lingkungan Pertanian dalam Masyarakat Agrari. Jurnal Cakrawala Pendidikan. November 1993. No.3, Tahun XII.

Tan, S. \& Waugh, R. 2013. Use of VirtualReality in Teaching and Learning Molecular Biology. In Cai, Y. (ed.), $3 D$ Immersive and Interactive Learning. Singapore: Springer Science Business Media Singapore.

Tjitroesoepomo, G. 2007. Taksonomi Tumbuhan (spermatophyta). yogyakarta: Gajah Mada University. 